\title{
Investigation on the structural changes of ZnO:Er:Yb thin film during laser annealing to fabricate a transparent conducting upconverter
}

\author{
Marta Lluscà ${ }^{a, b, *}$, Julian López-Vidrier ${ }^{c, d}$, Sara Lauzurica ${ }^{e}$, David Canteli $^{e}$, Maria I. \\ Sánchez-Aniorte ${ }^{e}$, Carlos Molpeceres ${ }^{e}$, Aldrin Antony ${ }^{a, f}$, Sergi Hernández ${ }^{c}, X_{\text {Xvier }}$ \\ Alcobég $^{g}$, Blas Garrido ${ }^{c}$ and Joan Bertomeu ${ }^{a}$
}

\author{
${ }^{a}$ Department of Applied Physics, Universitat de Barcelona, 08028 Barcelona, Spain \\ ${ }^{b}$ Now at Future Industries Institute, University of South Australia, Mawson Lakes, 5095 South Australia, \\ Australia \\ ${ }^{c}$ Department of Electronics, Universitat de Barcelona, 08028 Barcelona, Spain \\ ${ }^{d}$ Now at IMTEK, Faculty of Engineering, Albert-Ludwigs-University Freiburg, Georges-Köhler-Allee \\ 103, 79110 Freiburg, Germany \\ ${ }^{e}$ Centro Láser, Universidad Politécnica de Madrid, 28031 Madrid, Spain ${ }^{f}$ Indian Institute of Technology \\ Bombay, 400076 Mumbai, India \\ ${ }^{g}$ Unitat de Difracció de Raigs X, Centres Científics i Tecnològics, Universitat de Barcelona, 08028 \\ Barcelona, Spain
}

*corresponding author: marta.llusca@gmail.com

Keywords: upconversion, rare earth ions, TCO, solar cells, Erbium

A transparent and conducting $\mathrm{ZnO}: \mathrm{Er}: \mathrm{Yb}$ thin film with upconversion properties has been achieved after being annealed with continuous laser radiation just before the ablation point of the material. This work demonstrates that the laser energy preserves the conductivity of the film and at the same time creates an adequate surrounding for Er and $\mathrm{Yb}$ to produce visible upconversion at 660, 560, 520, and $480 \mathrm{~nm}$ under $980 \mathrm{~nm}$ laser excitation. The relation between the structural, electrical and upconversion properties is discussed. It is observed that the laser energy melts part of the material, which recrystallizes creating rare earth oxides and two different wurtzite structures, one with substitutional rare earths and oxygen vacancies (responsible for the conductivity) and the other without substitutional rare earth ions (responsible for the upconversion emission). 


\section{Introduction}

Rare earth (RE) ions have been widely studied concerning their photoluminescence (PL) properties, which can be exploited in lasers, phosphors, amplifiers, plasma displays and solar cells among others [1-3]. What all REs have in common is the fact that their $4 f$ inner shell is partially filled and spatially located within the lower-energy fully-filled $5 s, 5 p$ and $6 s$ subshells. As a consequence, the $4 f$ subshell is shielded and their electrons (responsible for the optical transitions) are barely affected by the surrounding, leading to many discrete energy levels in a wide spectral range $[4,5]$.

Among all the lanthanides, trivalent $\operatorname{Er}\left(\mathrm{Er}^{3+}, 4 \mathrm{f}^{11}\right)$ presents the capability of upconverting light from the infrared to the visible range. The characteristic Er electronic structure with equally spaced energy levels allows its excitation by two or more low energy photons, which results in the emission of a higher energy photon when the ion is relaxed. However, it is known that local surrounding of Er plays a critical role to facilitate its $4 f-4 f$ transitions to occur. The most suitable configuration is a pseudooctahedron structure with a $\mathrm{C}_{4 \mathrm{v}}$ symmetry, i.e., an Er atom placed at the center of an oxygen octahedron with unequal edge lengths ( $\mathrm{ErO}_{6}$ or $\mathrm{Er}_{2} \mathrm{O}_{3}$ clusters). In the case of wurtzite $\mathrm{ZnO}$, the site symmetry of any lattice atom is $\mathrm{C}_{3 \mathrm{v}}$ and the coordination is only tetrahedral. This means that a $\mathrm{RE}$ ion replacing $\mathrm{Zn}$ in the $\mathrm{ZnO}$ lattice does not act as an optically active center; non-stoichiometric growth, high deposition temperatures or annealing treatments are often necessary to achieve the proper Er local structure in the form of $\mathrm{ErO}_{6}$ clusters [6-10].

Upconversion systems are usually doped with two RE materials, one ion acting as the sensitizer, characterized by a long lifetime and a broad absorption spectrum, and the other ion, called the activator, acting as the emitter. It is common to use the Er and $\mathrm{Yb}$ couple [11-14], where $\mathrm{Yb}$ is the sensitizer and Er the activator. They cooperate together because their energy levels match for $\lambda=980 \mathrm{~nm}$ (see Fig. 1). In particular, $\operatorname{Er}{ }^{4} \mathrm{I}_{11 / 2}$ state can be populated by energy transfer from $\mathrm{Yb}$, which thus enhances the Er visible emission [15]. Indeed, up to date, the most efficient upconversion system has been reported to be for $\mathrm{Er}$ and $\mathrm{Yb}$ doped $\mathrm{NaYF}_{4}[16]$. 
The efficiency of solar cells is highly determined by the band gap $\left(E_{\mathrm{g}}\right)$ of the absorber (typically a semiconductor) material. As an example, a-Si:H solar cells only convert into electricity photons from energies close to its band gap of 1.7-1.8 eV: photons with smaller energies are not absorbed and photons with excessive energy are thermally lost [17]. Spectral conversion of the light wavelengths which are not absorbed by the solar cells could be an interesting method to enhance the overall efficiency of the solar cell [18]. In this regard, upconversion of low-energy photons to high-energy ones has recently gained great interest among the photovoltaics research community.

The objective of this study was to develop an upconverting material which can also function as an active layer in the device. Bearing in mind this purpose, we report the fabrication and properties of an upconverting transparent conducting oxide (TCO). Transparent conducting oxides like $\mathrm{ZnO}$ and ITO are an integral part of most of thin film solar cells as window layers, transparent electrical contacts, etc. In a-Si solar cells, $\mathrm{Al}$ - or B-doped $\mathrm{ZnO}$ is normally used to improve the optical properties of the back reflector and consequently acts as a diffusion barrier [19]. In this paper we explore the fabrication of an upconverting TCO film that can find application in various solar cells and other devices. One possible application is as the back reflector TCO for a-Si thin film solar cells. This TCO will facilitate the upconversion of photons with lower energy than the a-Si:H band gap of 1.7-1.8 eV to enhance the efficiency of the solar cell.

$\mathrm{ZnO}$ has been chosen to host $\mathrm{Er}$ and $\mathrm{Yb}$ ions, and a transparent and conducting $\mathrm{ZnO}: \mathrm{Er}: \mathrm{Yb}$ thin film has been deposited onto a glass substrate by means of radiofrequency (RF) magnetron sputtering. In order to optically activate the RE ions to achieve upconversion, a high temperature annealing treatment is necessary. According to previous results [20], ZnO:Er:Yb films post annealed either in air or in vacuum become almost insulating; instead, when the films were annealed with laser radiation, the rare earth ions were optically activated to present upconversion, whereas the films preserved the conductivity. This work presents the results on laser annealing of $\mathrm{ZnO}: \mathrm{Er}: \mathrm{Yb}$ films using $532 \mathrm{~nm}$ continuous wave (CW) laser radiation just before the damage threshold of the material, and confirms the effectiveness of this annealing treatment in achieving a transparent and conducting film that exhibits visible upconversion. A study on the morphology, structural, optical and electrical properties of ZnO:Er:Yb films, before and after the laser treatment, is presented. Finally, special 
attention is given to the correlation between the structure and the photoluminescence yielded by the samples.

\section{Experimental}

An 800-nm-thick ZnO:Er:Yb (0.5 at.\% for Er and 3 at.\% for Yb) thin film was deposited onto a $10 \times 10 \mathrm{~cm}^{2}$ Corning $1737 \mathrm{~F}$ glass substrate by means of RF magnetron sputtering. A custom-made target of $\mathrm{ZnO}: \mathrm{Er}_{2} \mathrm{O}_{3}: \mathrm{Yb}_{2} \mathrm{O}_{3}$ (89:1.2:9.8 wt\%) of 99.99\% purity and with a diameter of 3 inches was used for the sample preparation. The film was deposited at room temperature, at a working pressure of $0.4 \mathrm{~Pa}(\mathrm{Ar})$, using an $\mathrm{RF}$ power of $120 \mathrm{~W}$, and keeping a substrate rotation of $10 \mathrm{rpm}$. Ten samples of $10 \times 10$ $\mathrm{mm}^{2}$ were cut from the central part of the film: one of them was kept as a reference sample without any annealing treatment (AS DEP), another one was annealed at $800{ }^{\circ} \mathrm{C}$ during 1 hour in air atmosphere (AIR), and the eight remaining samples were laser annealed with a CW diode-pumped and frequency-doubled $\mathrm{Nd}: \mathrm{YVO}_{4}$ laser (SpectraPhysics Millennia Pro), providing an emission wavelength of $532 \mathrm{~nm}$ and a spot diameter of $29 \mu \mathrm{m}$ on the sample.

Laser annealing experiments were performed with energies around the damage threshold of the film (as determined from visual inspection). The idea was to provide enough energy to achieve the proper structural configuration for the realization of upconversion emissions without ablating the films. The laser annealing processes were performed by scanning $10 \times 10 \mathrm{~mm}^{2}$ areas with parallel lines. The laser parameters such as peak fluence, pitch between scans and number of overlapped scans that were employed are presented in Table I.

Table I. Sample names and laser parameters used to irradiate the $10 \times 10 \mathrm{~mm}^{2}$ samples of $\mathrm{ZnO}: \mathrm{Er}: \mathrm{Yb}$.

\begin{tabular}{cccc}
\hline Sample & $\begin{array}{c}\text { Peak fluence } \\
\left(\mathrm{J} / \mathrm{cm}^{2}\right)\end{array}$ & $\begin{array}{c}\text { Pitch } \\
(\mu \mathrm{m})\end{array}$ & $\begin{array}{c}\mathrm{N}^{\mathrm{o}} \text { of } \\
\text { scans }\end{array}$ \\
\hline 1 & 16.51 & 10 & 1 \\
2 & 8.25 & 10 & 1 \\
3 & 4.77 & 10 & 1 \\
4 & 13.21 & 30 & 1 \\
\hline
\end{tabular}




\begin{tabular}{llll}
\hline 5 & 2.13 & 10 & 1 \\
6 & 4.40 & 10 & 2 \\
7 & 4.40 & 10 & 4 \\
8 & 7.34 & 40 & 1 \\
\hline
\end{tabular}

The morphology, the structure and the electrical and optical properties of the films were studied before and after the different annealing treatments (air annealing and laser annealing). A confocal microscope and a Scanning Electron Microscope (SEM) were used to observe the morphology of the samples surface. The confocal microscope was a SENSOFAR Pl $\mu 2300$ equipped with an EPI objective of $20 \times$ magnification with optical resolution of $0.35 \mu \mathrm{m}$. The SEM instrument was a Jeol JSM-7100F and the images were taken using an electron beam of $20 \mathrm{KeV}$ and a maximum current of $36 \mathrm{nA}$, under backscattering configuration. The samples were covered with a carbon thin film before being imaged in the SEM. The structure of the films was analyzed using the Xray diffraction (XRD) technique (PANalyticalX'Pert PRO MPD Alpha1 powder system, using $\mathrm{Cu} K_{\alpha}$ radiation, $\lambda=1.5406 \AA$ ). The sheet resistance ( $\left.R s\right)$ was measured employing a four-point probe system (Jandel RM3). The optical transmittance spectra of all the samples were recorded in the range 400-1100 nm using a spectrophotometer (Perkin Elmer Lambda 950).

The upconversion photoluminescence (UC PL) measurements were carried out using an EKSPLA PG122 optic parametric oscillator (OPO) with output range 420-2300 nm, pumped by the third harmonic line (355 nm) of a Brilliant 5-ns-pulsed Nd:YAG laser (the peak power density was $\sim 10^{9} \mathrm{~W} \cdot \mathrm{cm}^{-2}$, the resulting beam size on the sample was $100 \mu \mathrm{m}$ in diameter). The OPO output was set at $980 \mathrm{~nm}$, aiming at the excitation of the ${ }^{4} \mathrm{I}_{11 / 2}$ and ${ }^{2} \mathrm{~F}_{5 / 2}$ levels of $\mathrm{Er}^{3+}$ and $\mathrm{Yb}^{3+}$ ions, respectively. The visible upconversion luminescence spectra from the samples were acquired using a GaAs photomultiplier tube coupled to a monochromator.

\section{Results and discussion}

Provided that the aim of the study was to anneal the samples around the ablation limit of the material, the probability to damage the films was very high. Thus, almost half of the samples underwent material losses. To observe the morphology of the treated samples, a confocal microscope was employed, and the resulting images are shown in Fig. 2. The 
inspection of the images revealed that samples 1 , 4, and 8 were highly damaged, as indicated by the dark stripes formed along the laser incidence path during annealing. In contrast, samples 2, 3, 5, 6, and 7 remained relatively unaffected except in reduced areas. To compare in more detail the effect of the laser treatment to the as-deposited and air-annealed samples, SEM was performed in samples AS DEP, AIR, 2 and 4 at two different magnifications (500× and 1000×) and the resulting images are shown in Fig. 3. As observed in the SEM micrographs and in agreement with the confocal images, the air-annealed sample and the laser treated sample 2 seem to have the same morphology as the as-deposited one. In contrast, sample 4, which was highly damaged, shows a rough surface with some cracks due to the laser ablation. Some evaporated carbon is observed in the AS DEP (50×) and AIR samples (500× and 1000×).

To identify the different crystalline phases present within the samples, XRD was performed on all the laser-treated samples, as well as on the air-annealed and the asdeposited ones. Fig. 4 displays all the obtained patterns. In general, all samples presented the most intense diffraction peak at around $2 \theta=33.5-34.5^{\circ}$, suggesting the typical $\mathrm{ZnO}$ hexagonal wurtzite structure with the $c$-axis perpendicular to the sample surface. Nevertheless, as observed in the as-deposited sample, the peak was not symmetric, indicating that a second peak was also involved. Moreover, when this sample was laser treated and the energy was high enough (see for example samples 1 and 4), a peak splitting was clearly observed that suggests the coexistence of two different wurtzite structures in the same sample. In addition, in the case of laser-treated samples with the highest peak fluence, a peak appeared at $2 \theta=29.62^{\circ}$ corresponding to the (222) reflection of $\mathrm{Yb}_{2} \mathrm{O}_{3}$ cubic structure. These results seem to indicate that $\mathrm{Yb}$, which was initially substituting $\mathrm{Zn}$ in the $\mathrm{ZnO}$ lattice or at the grain boundaries before annealing, migrated to form $\mathrm{Yb}_{2} \mathrm{O}_{3}$ due to the high amount of energy received. It must be mentioned that no $\mathrm{Er}_{2} \mathrm{O}_{3}$-related peaks were observed due to the small amount of $\mathrm{Er}$ content in the films (0.5 at.\%).

For a better understanding on the ZnO:Er:Yb structural changes, a more detailed comparison between the as-deposited sample, the air-annealed one and sample 4 is presented in Fig. 5 and Fig. 6. The as-deposited sample revealed just two peaks that correspond to the first- and second-order diffraction of a typical wurtzite structure, respectively (002) and (004). Due to the clear asymmetry in both peaks, a deconvolution 
in two pseudo-Voigt functions has been performed to identify the exact peak positions (see Fig. 6). The first peak was centered at $33.53^{\circ}$ (corresponding to $c_{1}=0.534 \mathrm{~nm}$ ) and the second at $34.11^{\circ}\left(c_{2}=0.525\right)$, which suggests the presence of two different wurtzite $\mathrm{ZnO}$ structures, each of them with different lattice parameters. These two structures have been referred as wurtzite $1\left(\mathrm{~W}_{1}\right)$ and wurtzite $2\left(\mathrm{~W}_{2}\right)$, respectively.

When the sample was air-annealed, $\mathrm{Yb}_{2} \mathrm{O}_{3}$ was formed in its cubic structure with (222) orientation. Furthermore, results seem to indicate that, in this case, only the $\mathrm{W}_{2}$ wurtzite structure of $\mathrm{ZnO}$ is present in the sample.

When the sample was laser annealed at high energy, like in the case of sample 4, the (002) peak experienced a splitting into two peaks that we identified as $W_{1}$ and $W_{2}$. In addition, other orientations belonging to $W_{2}$ also appeared in the sample. A peak corresponding to $\mathrm{Yb}_{2} \mathrm{O}_{3}$ was also observed at $31.86^{\circ}$. This substantial difference on the lattice structure between the as-deposited sample and the laser-annealed one suggests that the laser annealing might have melted the film and, when it cooled down, it recrystallized with a different structure, consisting in the coexistence of two wurtzite structures rich in $\mathrm{ZnO}$ and also some cubic structure of $\mathrm{Yb}_{2} \mathrm{O}_{3}$. Even so, to completely establish that two wurtzite structures are coexisting with $\mathrm{RE}_{2} \mathrm{O}_{3}$ and/or $\mathrm{REO}_{6}$ clusters, further structural characterization should be performed.

The $c$-parameter was calculated for $\mathrm{W}_{1}$ and $\mathrm{W}_{2}$ in all the samples, whereas the lattice parameter $a$ could only be calculated for the samples 1, 4 and 8 from the (102) peak position. Table II summarizes all the calculated lattice parameter values. $\mathrm{W}_{1}$ had lattice parameters values much higher than the stress-free $\mathrm{ZnO}$ powder value $(c=0.521 \mathrm{~nm})$ and also larger than that for sputtered and undoped $\mathrm{ZnO}(c=0.523 \mathrm{~nm}$, as calculated in Ref. [15]), indicating a very high compressive stress caused mainly by the large ionic radius of the REs species, which distort the lattice once placed in substitutional $\mathrm{Zn}$ sites. Instead, $\mathrm{W}_{2}$ exhibited closer values to the standard one, suggesting that the RE ions migrated from these substitutional positions into other sites in or outside the lattice, inducing a more stress-free film.

Table II. Values of the lattice parameters for the two wurtzite structures $\left(\mathrm{W}_{1}\right.$ and $\mathrm{W}_{2}$ ), for the as-deposited, air-annealed and for the 8 samples irradiated with different laser parameters. 


\begin{tabular}{cccc}
\hline Sample & $c_{1}(\mathrm{~nm})$ & $c_{2}(\mathrm{~nm})$ & $a_{2}(\mathrm{~nm})$ \\
\hline AS DEP & 0.534 & 0.525 & - \\
1 & 0.534 & 0.519 & 0.314 \\
2 & 0.535 & 0.528 & - \\
3 & 0.534 & 0.525 & - \\
4 & 0.534 & 0.519 & 0.313 \\
5 & 0.534 & 0.525 & - \\
6 & 0.535 & 0.519 & - \\
7 & 0.536 & 0.519 & - \\
8 & 0.528 & 0.513 & 0.318 \\
AIR & - & 0.520 & - \\
\hline
\end{tabular}

As a general trend, it is observed that the lowest laser energies maintain the XRD patterns unchanged. Nevertheless, when increasing the laser peak fluence or decreasing the pitch, the (002) peak started to split and Yb began to oxidize. Finally, when the energy was very high (like in sample 1) the surface was highly damaged, the peaks intensity decreased and even the $\mathrm{Yb}_{2} \mathrm{O}_{3}$ phases disappeared, probably ascribed to a recrystallization of the material.

To evaluate the feasibility as a transparent and conducting film, the Rs and the transmittance were measured. A summary of the Rs values is shown in Table III along with the integrated transmittance values in the range 400-1100 $\mathrm{nm}$. The electrical conductivity of as-deposited $\mathrm{ZnO}$ :Er:Yb films is due to the contribution of $\mathrm{Er}^{3+}$ and $\mathrm{Yb}^{3+}$ ions incorporated at the substitutional sites of $\mathrm{Zn}^{2+}$ ions, as well as to the presence of oxygen vacancies and zinc interstitials [21]. When the film was annealed in air, the Rs drastically increased to $10^{4} \mathrm{k} \Omega / \mathrm{sq}$ due to the filling up of oxygen vacancies and/or to the chemisorption of $\mathrm{O}_{2}$ [21-23]. A significant improvement in the transparency was observed for this sample due to the oxygen incorporation. In the laser-treated samples, the Rs behaved according to the morphology of the samples: higher ablation corresponded to higher Rs due to the non-uniform loss of material. When the samples did not present a damaged surface, the Rs kept invariable. The same happened with the transmittance of the films: only the damaged films exhibited lower transmittance values, whereas they looked unchanged if the morphology was unaltered. In accordance to these results, samples 2, 3, 5, 6 and 7 could be used as the transparent and conducting oxide of the back reflector of a $p-i-n$ thin film Si solar cell. On the contrary, samples 1 and 4 showed too low conductivity and transmittance due to the damaged surface. 
Table III: Values of the $R s$ and the integrated $T$ in the range $400-1100 \mathrm{~nm}$ corresponding to the 8 laser-treated samples and the as-deposited and air-annealed ones.

\begin{tabular}{ccc}
\hline Sample & $R s(\mathrm{k} \Omega / \mathrm{sq})$ & $T_{(400-1100 \mathrm{~nm})}(\%)$ \\
\hline AS DEP & $2-10$ & 83.8 \\
1 & $100-130$ & 63.1 \\
2 & 3 & 83.9 \\
3 & 45 & 83.5 \\
4 & 2000 & 78.7 \\
5 & 2 & 85.2 \\
6 & 10 & 83.7 \\
7 & 2.6 & 84.3 \\
8 & - & 81.5 \\
AIR & 10000 & 88.3 \\
\hline
\end{tabular}

The next step to check the adequacy of $\mathrm{ZnO}: \mathrm{Er}: \mathrm{Yb}$ as a back reflector TCO was to analyze its upconversion properties. With this aim, upconversion PL of the RE-based films was measured, the resulting spectra being displayed in Fig. 7. As can be observed in the figure, the as-deposited ZnO:Er:Yb presented UC emission at $660 \mathrm{~nm}$ without the need of any annealing treatment. This is in contrast to what was observed in previous experiments $[15,20]$, in which the doping level was obtained by placing the RE pellets on the erosion area of the $\mathrm{ZnO}$ target. In this work, however, the target was already a mixture of $\mathrm{ZnO}$, $\mathrm{Er}$ and $\mathrm{Yb}\left(\mathrm{ZnO}_{\mathrm{Er}_{2} \mathrm{O}_{3}}(1.2 \mathrm{wt} \%): \mathrm{Yb}_{2} \mathrm{O}_{3}\right.$ (9.8 wt\%)), which sensibly modified the sample structure with respect to these publications, in such a way as previously discussed in this section.

As expected, after the air annealing treatment this UC PL (at $\lambda \sim 660 \mathrm{~nm}$ ) was drastically increased. In Er-Yb systems, the most probable excitation mechanism concerns the $\mathrm{Yb}^{3+}$ ${ }^{2} \mathrm{~F}_{7 / 2} \rightarrow{ }^{2} \mathrm{~F}_{5 / 2}$ transition, whose emission populates the ${ }^{4} \mathrm{I}_{11 / 2}$ and ${ }^{4} \mathrm{~F}_{7 / 2}$ excited states of $\mathrm{Er}^{3+}$ ions via multiple photon absorption. After relaxation of the ${ }^{4} \mathrm{~F}_{7 / 2}$ state to the intermediate ${ }^{2} \mathrm{H}_{11 / 2},{ }^{4} \mathrm{~S}_{3 / 2}$, and ${ }^{4} \mathrm{~F}_{9 / 2}$ ones, its radiative decay to the ground state $\left({ }^{4} \mathrm{I}_{15 / 2}\right)$ originates visible emission peaks at $\sim 520, \sim 560$ and $\sim 660 \mathrm{~nm}$, respectively, whereas the $\sim 480 \mathrm{~nm}$ emission is due to the direct radiative transition ${ }^{4} \mathrm{~F}_{7 / 2} \rightarrow{ }^{4} \mathrm{I}_{15 / 2}$.

In the air-annealed sample, however, only emission at $660 \mathrm{~nm}$ is observed. Various factors could be responsible of changing the emission ratio of green and blue to red for $\mathrm{Er}^{3+}$ doped materials under $980 \mathrm{~nm}$ wavelength excitation: coordination number, site 
symmetry or short interatomic distances could be some of the reasons [24-31].The distance between the Er and Yb within the host material is known to play an important role in determining the UC emission ratios of $\mathrm{Er}^{3+}$ ions. It has been reported that a shorter spacing between $\mathrm{Er}$ and $\mathrm{Yb}$ or Er and Er ions may result in stronger cross relaxation processes which would decrease the population in the green emission levels $\left({ }^{2} \mathrm{H}_{11 / 2}\right.$ and ${ }^{4} \mathrm{~S}_{3 / 2}$ levels) and increase the population in the red emission level $\left({ }^{4} \mathrm{~F}_{9 / 2}\right.$ energy level) [24]. As a consequence, single band red emission can be observed. Similar behaviour for the couple $\mathrm{Er} / \mathrm{Yb}$ has been reported in other systems such as $\mathrm{KMgF}_{3}$ [29], $\mathrm{KMnF}_{3}$ [30] and $\mathrm{NaMnF}_{3}$ [31].

On the other hand, the laser-treated samples presented these other visible UC emissions. In general, the observations show an enhanced UC PL when the damage caused by the ablation was more evident. This statement is supported by samples 1,4 and 8 (presenting the most damaged surfaces, as seen in Fig. 2 and as determined from visual inspection), which exhibited very high UC intensities. Nevertheless, a direct comparison between sample intensities cannot be done because of the lack of homogeneity in the $10 \times 10 \mathrm{~cm}^{2}$ thin film surface. Some previous characterization was performed comparing two as- deposited pieces taken from the lateral and from the center of the whole $10 \times 10$ $\mathrm{cm}^{2}$ area, and their optical, structural and electrical characterization on those pieces indicate that the surface was not completely homogeneous. Moreover, slight deviations in either the focus or alignment during PL might be responsible for additional UC-PL intensity uncertainties from spectrum to spectrum, but without affecting their lineshape. Laser-annealed sample 1 exhibits a lower intensity ratio between the $488 \mathrm{~nm}$ and 550 and $520 \mathrm{~nm}$ transitions when compared to the rest of the samples. This occurrence could be relate to an increase of the non-radiative decay probability to the ${ }^{4} \mathrm{~F}_{7 / 2}$ level to the lower energy ${ }^{2} \mathrm{H}_{11 / 2},{ }^{4} \mathrm{~S}_{3 / 2}$, and ${ }^{4} \mathrm{~F}_{9 / 2}$ states (see schematics in Fig. 1); actually, the disappearance of $\mathrm{Yb}_{2} \mathrm{O}_{3}$ domains from sample 1 after laser damage, as observed by XRD measurements, supports the UC-PL observations of higher ${ }^{4} F_{7 / 2}$ level instability. When comparing the UC PL to the conductivity and transparency of the samples, it could be demonstrated that it is possible to achieve a transparent and conducting upconverter. In particular, as shown by samples 2, 5, and 7, the Rs was lower than 3 $\mathrm{k} \Omega / \mathrm{sq}$, the integrated transmittance in the range $400-1100 \mathrm{~nm}$ was higher than $\sim 84 \%$ and visible UC emission was achieved at $\sim 480, \sim 520, \sim 550$, and $\sim 660 \mathrm{~nm}$. Correlating the structural patterns to the PL results, the first observation was that the highest 
upconversion was given by the sample annealed in air, the one that contained the highest amount of $\mathrm{Yb}_{2} \mathrm{O}_{3}$ crystals and in which only the $\mathrm{W}_{2}$ structure was seen. Rareearth oxides possess the adequate configuration to allow optical transitions to occur [10]; hence, higher $\mathrm{Yb}_{2} \mathrm{O}_{3}$ means higher UC efficiency. Moreover the RE ions forming $\mathrm{RE}_{2} \mathrm{O}_{6}$ complexes inside or outside the $\mathrm{ZnO}$ matrix will also lead to UC emission. Therefore, the total UC luminescence must be ascribed to the contribution of $\mathrm{RE}_{2} \mathrm{O}_{3}$ and $\mathrm{RE}_{2} \mathrm{O}_{6}$ complexes. Although those complexes could not be detected through XRD, it is probable that the RE in substitutional sites formed $\mathrm{W}_{1}$ and the $\mathrm{RE}$ in non-substitutional sites formed $\mathrm{W}_{2}$. Then, the probability to have $\mathrm{Er}_{2} \mathrm{O}_{6}$ complexes was higher if the REs were not substituting zinc and the contribution of $\mathrm{W}_{2}$ was higher. The coexistence of $\mathrm{W}_{1}$ and $\mathrm{W}_{2}$ could be the reason why the conductivity remained in the non-ablated samples after laser annealing. As mentioned before, the conductivity in ZnO:Er:Yb films can be either due to substitutional $\mathrm{RE}$ in the $\mathrm{ZnO}$ lattice or to oxygen vacancies; therefore, $\mathrm{W}_{1}$ seemed to be the structure responsible of the electrical conduction. It was also observed that the higher was the ablation, the more evident was the (002) peak splitting and the more enhanced was the UC emission. In conclusion, the UC seemed to be related to the appearance of $\mathrm{W}_{2}$ and $\mathrm{Yb}_{2} \mathrm{O}_{3}$ phases, whereas the conductivity could be related to $\mathrm{W}_{1}$. As an inference from the obtained results, the coexistence of $\mathrm{W}_{1}, \mathrm{~W}_{2}$ and $\mathrm{Yb}_{2} \mathrm{O}_{3}$ phases in $\mathrm{ZnO}: \mathrm{Er}: \mathrm{Yb}$ films could result in a material with both conducting and upconverter characteristics.

\section{Conclusions}

The aim of this work was to fabricate a transparent and conducting upconverter at low process temperature. For this, $\mathrm{ZnO}$ has been doped with $\mathrm{Er}$ and $\mathrm{Yb}$ and has been postannealed under air atmosphere and under laser radiation in order to optically activate the RE ions. To be an optically active center, the RE ion needs to be surrounded by 6 oxygen atoms in a distorted octahedron configuration. As-deposited $\mathrm{ZnO}: \mathrm{Er}: \mathrm{Yb}$ is transparent and conducting but shows a weak UC photoluminescence because Er replacing zinc in the $\mathrm{ZnO}$ lattice is not surrounded by 6 oxygen atoms. Hence, a postdeposition annealing treatment is needed. When the films are annealed in air, enhanced visible UC emission is produced at $660 \mathrm{~nm}$ under $980 \mathrm{~nm}$ laser excitation but the films become almost insulating. By using $\mathrm{CW}$ laser to anneal the samples just before the ablation limit of the material, the electrical properties are completely maintained and 
high UC is achieved at 660, 560, 520, and $480 \mathrm{~nm}$. The structural and PL characterization of all the samples suggests that UC comes from clusters of $\mathrm{REO}_{6}$ as well as from $\mathrm{RE}_{2} \mathrm{O}_{3}$ inside or outside the matrix. The as-deposited films have a lack of oxygen which yields to almost non-luminescent samples. When they are annealed in air, the oxygen from the air binds to the RE species that migrate from substitutional sites and from the grain boundaries to form $\mathrm{RE}$ oxides or $\mathrm{REO}_{6}$ complexes. However, the laser annealing seems to be able to preserve the electrical properties while producing optically active centers. Supported by the experimental results, we believe that the laser energy is melting part of the material which recrystallizes creating RE oxides and two wurtzite structures, one that has substitutional REs and oxygen vacancies (which is responsible for the conductivity) and the other without substitutional REs (which is responsible for $\mathrm{UC}$ emission through the formation of $\mathrm{REO}_{6}$ complexes). Overall, the observations so far suggest the suitability of laser-annealed ZnO:Er:Yb thin films as an upconverting transparent conducting oxide. This upconverting TCO could match the requisites for many applications, such as the back TCO in thin film a-Si solar cells aiming at the spectral exploitation of the near IR wavelength.

\section{Acknowledgments}

This work was supported by the Spanish Ministerio de Economía y Competitividad through the projects HELLO (ENE2013-48629-C4-2/3-R) and LEOMIS (TEC201238540-C02-01).

\section{References}

[1] S. Hilderbrand, F. Shao, C. Salthouse, U. Mahmood, R. Weissleder, Luminescent Nanomaterials: Application to In Vivo Bioimaging, Chem. Commun. 28 (2009) 4188-4190.

[2] C. W. Thiel, Y. Sun, R. L. Cone, Progress in Relating Rare-Earth Ion 4f and 5d Energy Levels to Host Bands in Optical Materials for Hole Burning, Quantum Information, and Phosphors, J. Mod. Optic. 49 (2002) 2399-2411.

[3] H. Q. Wang, M. Batentschuk, A. Osvet, L. Pinna, C. J. Brabec, Rare Earth Ion Doped Up-conversion Materials for Photovoltaic Applications, Adv. Mater. 23 (2011) 2675-2680. 
[4] B. M. van der Ende, L. Aarts, A. Meijerink, Lanthanide Ions as Spectral Converters for Solar Cells, Phys. Chem. Chem. Phys. 11 (2009) 11081-11095.

[5] G. H. Dieke, The Spectra of the Doubly and Triply Ionized Rare Earths, Appl. Optics, 2 (1963) 675-686.

[6] A. J. Kenyon, Recent Developments in Rare-Earth Doped Materials for Optoelectronics, Prog. Quant. Electron. 26 (2002) 225-284.

[7] L. Douglas, R. Mundle, R. Konda, C. E. Bonner, A. K. Pradhan, D. R. Sahu, J. L. Huang, Influence of Doping Rate in $\mathrm{Er}^{3+}: \mathrm{ZnO}$ Films on Emission Characteristics, Opt. Lett. 33 (2008) 815-817.

[8] Z. Zhou, T. Komaki, A. Koizumi, T. Komori, M. Yoshino, M. Morinaga, Y. Fujiwara, Y. Takeda, Photoluminescence around $1.54 \mu \mathrm{m}$ from Er-containing $\mathrm{ZnO}$ at Room Temperature, Mater. Trans. 45 (2004) 2003-2007.

[9] X. Wang, X. Kong, Y. Yu, Y. Sun, H. Zhang, Effect of Annealing on Upconversion Luminescence of ZnO:Er 3+ Nanocrystals and High Thermal Sensitivity, J. Phys. Chem. 111 (2007) 15119-15124.

[10] M. Ishii, T. Ishikawa, T. Ueki, S. Komuro, T. Morikawa, Y. Aoyagi, H. Oyanagi, The Optically Active Center and its Activation Process in Er-doped Si Thin Film Produced by Laser Ablation, J. Appl. Phys. 85 (1999) 4024-4031.

[11] X. Meng, C. Liu, F. Wu, J. Li, Up-conversion Emissions in ZnO:Er3+, ZnO:Er(3+)-Yb3+ Nanoparticles and Their Surface Modified Counterparts, J. Colloid Interface Sci. 358 (2011) 334-337.

[12] J. F. Philipps, T. Töpfer, D. Ehrt, R. Sauerbrey, Lasing Properties of Er3+: Yb3+ doped, Appl. Phys. B. 405 (2001) 399-405.

[13] A. S. Oliveira, M. T. de Araujo, A. S. Gouveia-Neto, J. A. Medeiros Neto, A. S. B. Sombra, Y. Messaddeq, Frequency upconversion in Er3+/Yb3+-codoped chalcogenide glass, Appl. Phys. Lett. 72 (1998) 753-755.

[14] M. Wang, C. Mi, W. Wang, C. Liu, Y. Wu, Z. Xu, B. Mao, S. Xu, Immunolabeling and NIR-excited fluorescent imaging of HeLa cells by using NaYF4:Yb,Er upconversion nanoparticles, ACS nano. 3 (2009) 1580-1586.

[15] M. Lluscà, J. López-Vidrier, A. Antony, S. Hernández, B. Garrido, J. Bertomeu, Up-conversion effect of Er- and Yb-doped ZnO thin films, Thin Solid Films, 562 (2014) 456-461. 
[16] J. Suyver, J. Grimm, K. Krämer, H. Güdel, Highly efficient near-infrared to visible up-conversion process, J. Lumin. 114 (2005) 53-59.

[17] B. Richards, Enhancing the performance of silicon solar cells via the application of passive luminescence conversion layers, Sol. Energ. Mat. Sol. C. 90 (2006) 2329-2337. [18] W. G. van Sark, J. de Wild, J. Rath, A. Meijerink, R. Schropp, Upconversion in solar cells, Nanoscale Res. Lett. 8 (2013) 881.

[19] J. Morris, R. R. Arya, J. G. O'Dowd, S. Wiedeman, Absorption enhancement in hydrogenated amorphous silicon based solar cells, J. Appl. Phys. 47 (1990) 4086.

[20] M. Lluscà, J. López-Vidrier, S. Lauzurica, M. I. Sánchez-Aniorte, A. Antony, C. Molpeceres, S. Hernández, B. Garrido, J. Bertomeu, Activation of visible up-conversion luminescence in transparent and conducting $\mathrm{ZnO}: \mathrm{Er}: \mathrm{Yb}$ films by laser annealing, J. Lumin. 167 (2015) 101-105.

[21] H. Tong, Z. Deng, Z. Liu, C. Huang, J. Huang, H. Lan, C. Wang, Y. Cao, Effects of post-annealing on structural, optical and electrical properties of Al-doped $\mathrm{ZnO}$ thin films, Appl. Surf. Sci. 257 (2011) 4906-4911.

[22] B. L. Zhu, X. H. Sun, X. Z. Zhao, F. H. Su, G. H. Li, X. G. Wu, J. Wu, R. Wu, J. $\mathrm{Liu}$, The effects of substrate temperature on the structure and properties of $\mathrm{ZnO}$ films prepared by pulsed laser deposition, Vacuum, 82 (2008) 495-500.

[23] S. S. Lin, J. L. Huanga, P. Sajgalik, The properties of heavily Al-doped ZnO films before and after annealing in the different atmosphere, Surf. Coat. Technol. 185 (2004) 254-263.

[24] W. Wei, Y. Zhang, R. Chen, J. L. Goggi, N. Ren, L. Huang, K. K. Bhakoo, H. D. Sun, T. T. Y. Tan, Cross Relaxation Induced Pure Red Upconversion in Activator- and Sensitizer-Rich Lanthanide Nanoparticles, Chem. Mater. 26 (2014) 5183-5186.

[25] M. Pang, X. S. Zhai, J. Feng, S. Y. Song, R. P. Deng, Z. Wang, S. Yao, X. Ge, H. J. Zhang, One-step synthesis of water-soluble hexagonal $\mathrm{NaScF}_{4}: \mathrm{Yb} / \mathrm{Er}$ nanocrystals with intense red emission, Dalton Trans. 43 (2014) 10202-10207.

[26] Y. G. Wang, T. Wen, H. N. Zhang, J. Sun, M. Zhang, Y. Z. Guo, W. J. Luo, M. J. Xia, Y. X. Wang, B. C. Yang, Low-Temperature Fluorination Route to LanthanideDoped Monoclinic ScOF Host Material for Tunable and Nearly Single Band UpConversion Luminescence, J. Phys. Chem. C 118 (2014) 10314-10320.

[27] X. Teng, Y. H. Zhu, W. Wei, S. C. Wang, J. F. Huang, R. Naccache, W. B. Hu, A. I. Y. Tok, Y. Han, Q. C. Zhang, Q. L. Fan, W. Huang, J. A. Capobianco, L. Huang, 
Lanthanide-Doped $\mathrm{Na}_{\mathrm{x}} \mathrm{ScF}_{3+\mathrm{x}}$ Nanocrystals: Crystal Structure Evolution and Multicolor Tuning, J. Am. Chem. Soc. 134 (2012) 8340-8343.

[28] Y. J. Ding, X. Teng, H. Zhu, L. L. Wang, W. B. Pei, J. J. Zhu, L. Huang, W. Huang, Orthorhombic $\mathrm{KSc}_{2} \mathrm{~F}_{7}: \mathrm{Yb} / \mathrm{Er}$ nanorods: controlled synthesis and strong red upconversion emission, Nanoscale, 5 (2013) 11928-11932.

[29] M. Wu, E. H. Song, Z. T. Chen, S. Ding, S. Ye, J. J. Zhou, S. Q. Xu, Q. Y. Zhang, Single-band red upconversion luminescence of $\mathrm{Yb}^{3+}-\mathrm{Er}^{3+}$ via nonequivalent substitution in perovskite $\mathrm{KMgF}_{3}$ nanocrystals, J. Mater. Chem. C 4 (2016) 1675-1684. [30] J. Wang, F. Wang, C. Wang, Z. Liu, X. Liu, Single-Band Upconversion Emission in Lanthanide-Doped $\mathrm{KMnF}_{3}$ Nanocrystals, Angew. Chem. Int. Ed. 50 (2011) 1036910372.

[31] Y. Zhang, J. D. Lin, V. Vijayaragavan, K. K. Bhakoo, T. T. Y. Tan, Tuning sub-10 nm single-phase $\mathrm{NaMnF}_{3}$ nanocrystals as ultrasensitive hosts for pure intense fluorescence and excellent T1 magnetic resonance imaging, Chem. Commun. 48 (2012) 10322-10324.

\section{Figure captions}

Fig. 1. Generic representation of Er/Yb energy transfer; the radiative decay is shown with the full vertical arrows, the dashed ones depict upconversion processes and the multi-phonon relaxation is indicated by the curly lines. Energy transfer processes are sketched by Yb-to-Er solid arrows. Russel-Saunders ${ }^{(2 S+1)} \mathrm{L}_{J}$ notation was employed to refer to the f states: spin (S), orbital (L) and angular momentum (J) quantum numbers.

Fig. 2. Confocal microscope images of all the laser-annealed ZnO:Er:Yb samples and the as-deposited one (AS DEP).

Fig. 3. SEM images of the ) AS DEP , b) AIR , c) 2 and d) 4 samples. The left images correspond to a magnification of $500 \times$, whereas the right ones were acquired with a magnifcation of $1000 \times$.

Fig. 4. X-ray diffraction patterns, in logarithmic scale, of the laser treated samples along with the as-deposited and the air-annealed samples. 
Fig. 5. X-ray diffraction patterns, in logarithmic scale, of the as-deposited sample, the air-annealed one and sample 4 (laser-annealed), with $2 \theta$ values ranging from $20^{\circ}$ to $75^{\circ}$.

Fig. 6. X-ray diffraction patterns, in linear scale, of the as-deposited sample, the airannealed one and laser-annealed sample 4 , with $2 \theta$ values ranging from $31^{\circ}$ to $37^{\circ}$.

Fig. 7. Upconversion PL emission spectra, in logarithmic scale, of the laser-treated ZnO:Er:Yb samples and the air-annealed and the as-deposited ones. The laser source excitation wavelength was fixed at $980 \mathrm{~nm}$. 
Figure 1

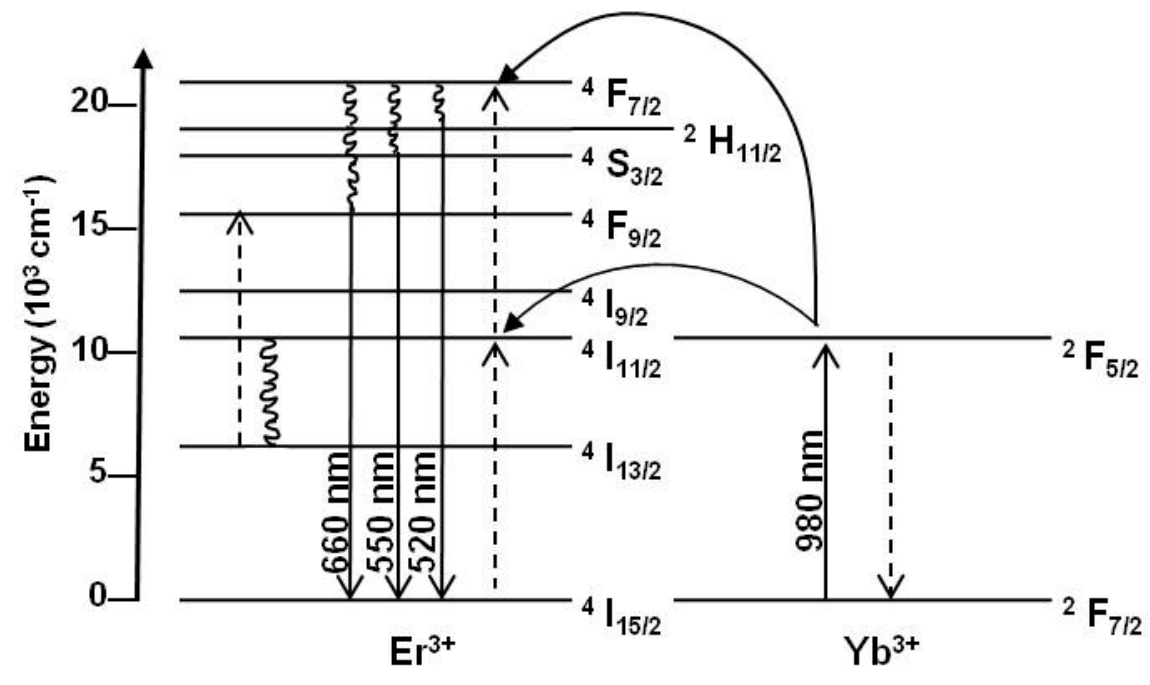


Figure 2

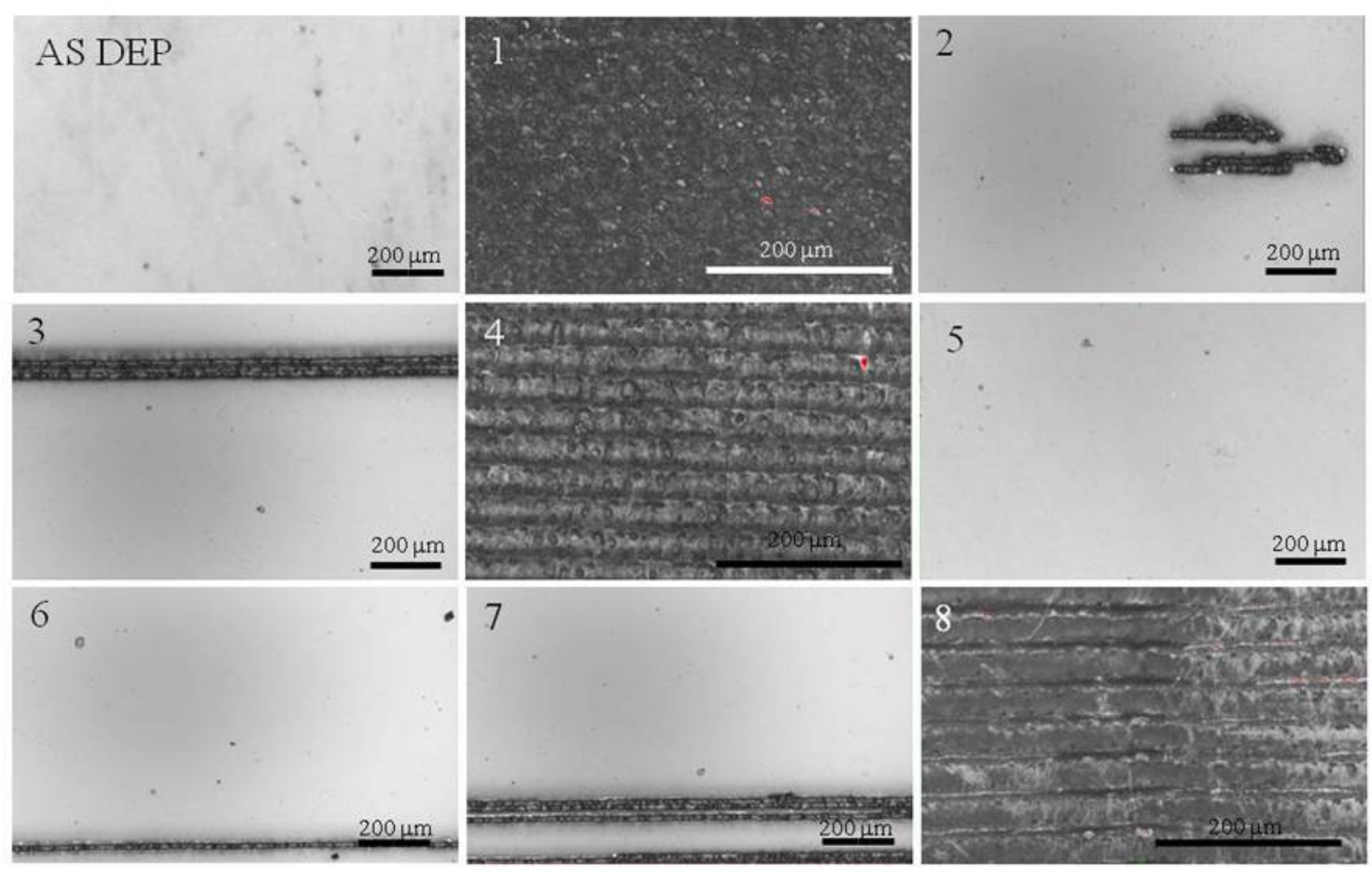


Figure 3

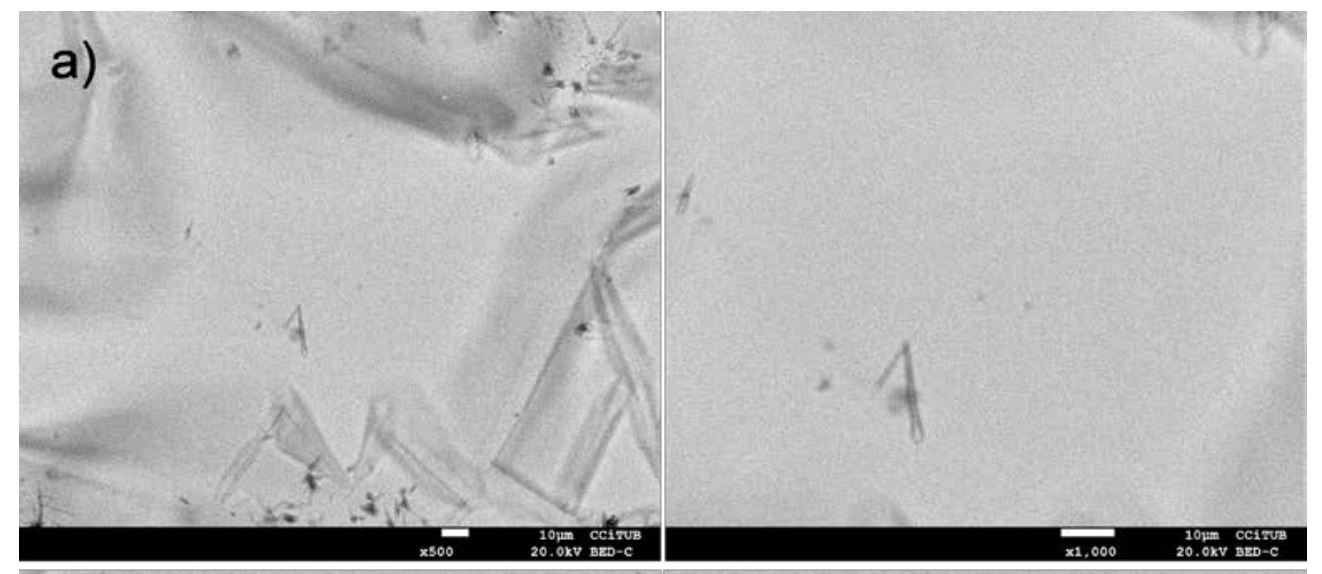

b)
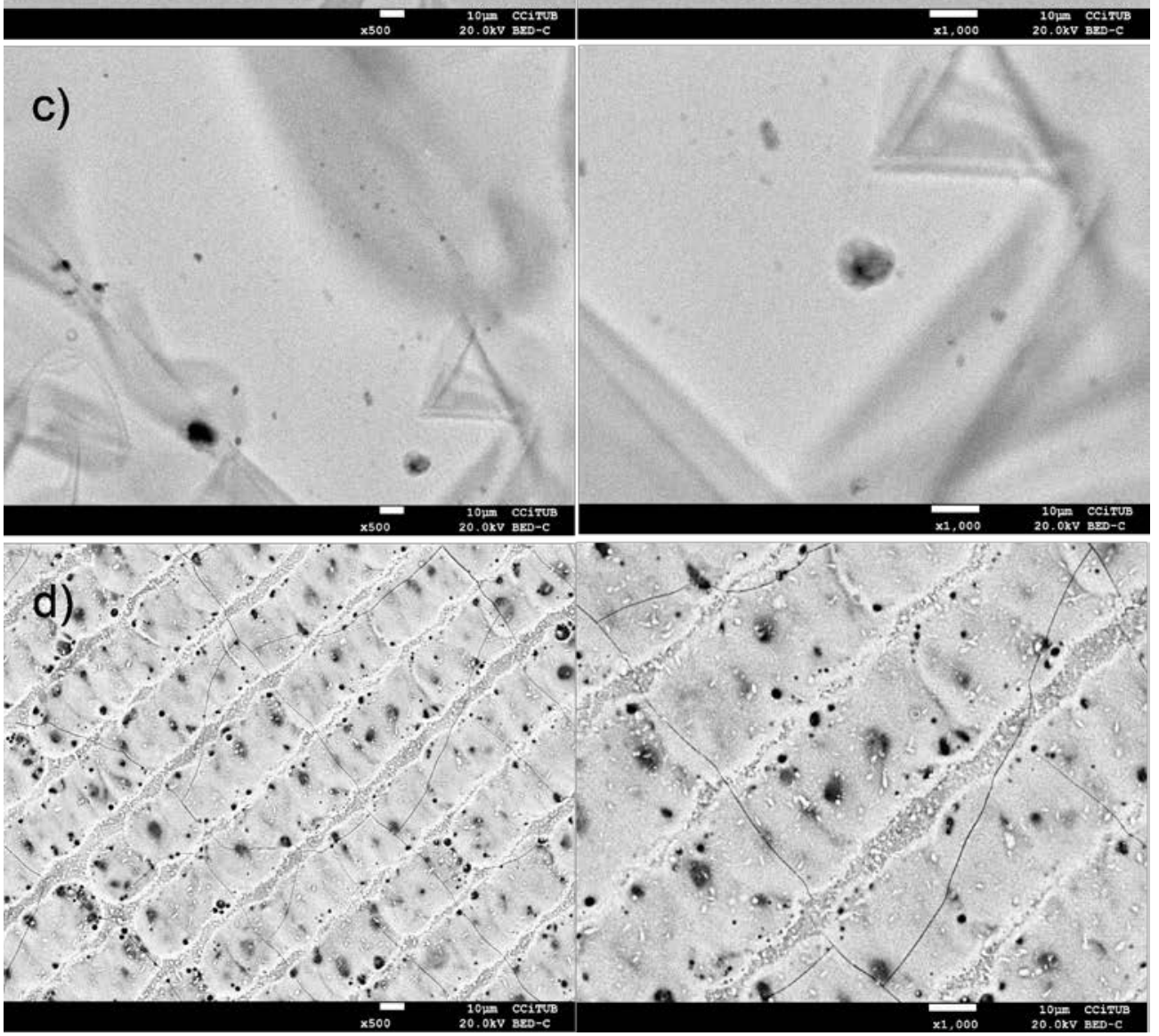
Figure 4

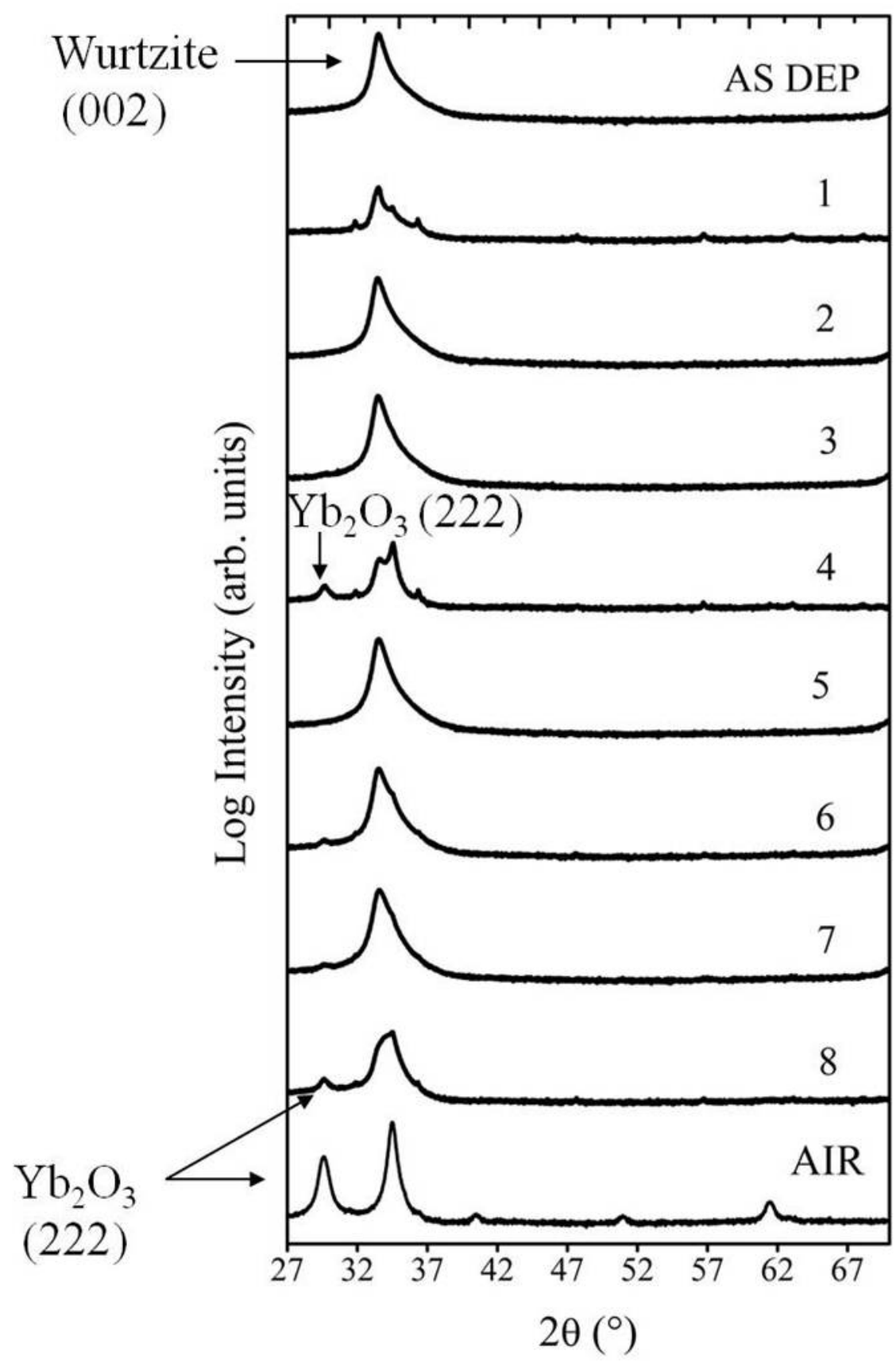


Figure 5

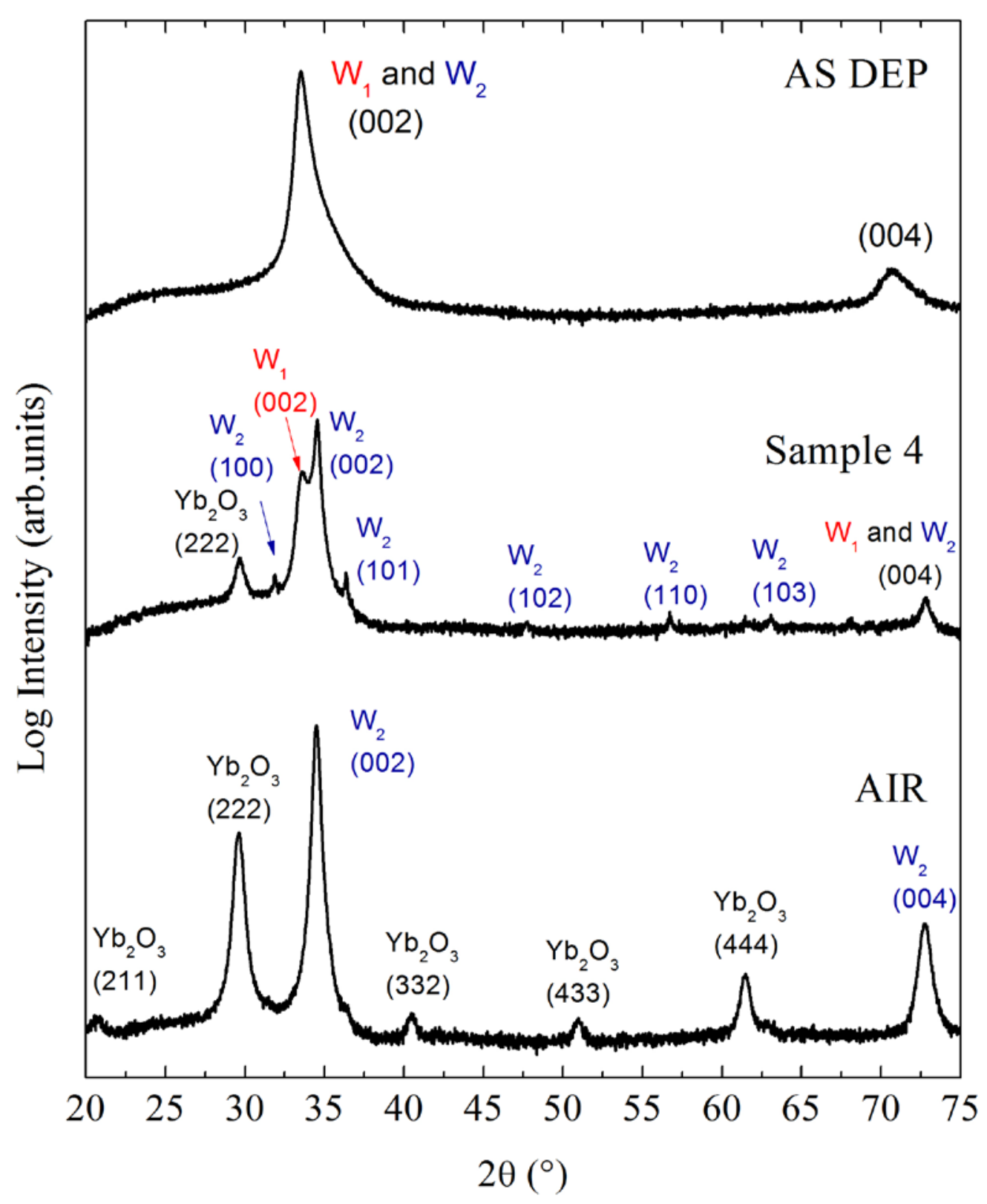


Figure 6

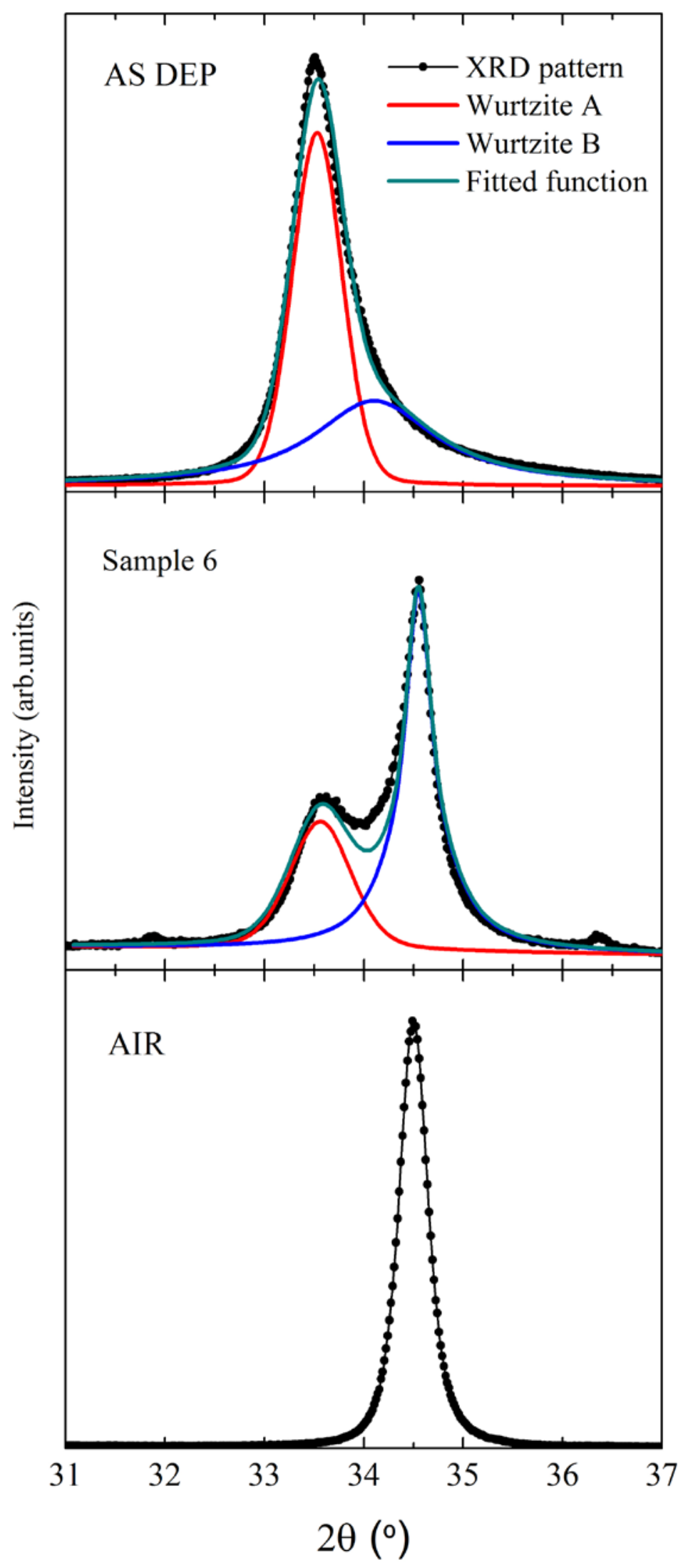


Figure 7

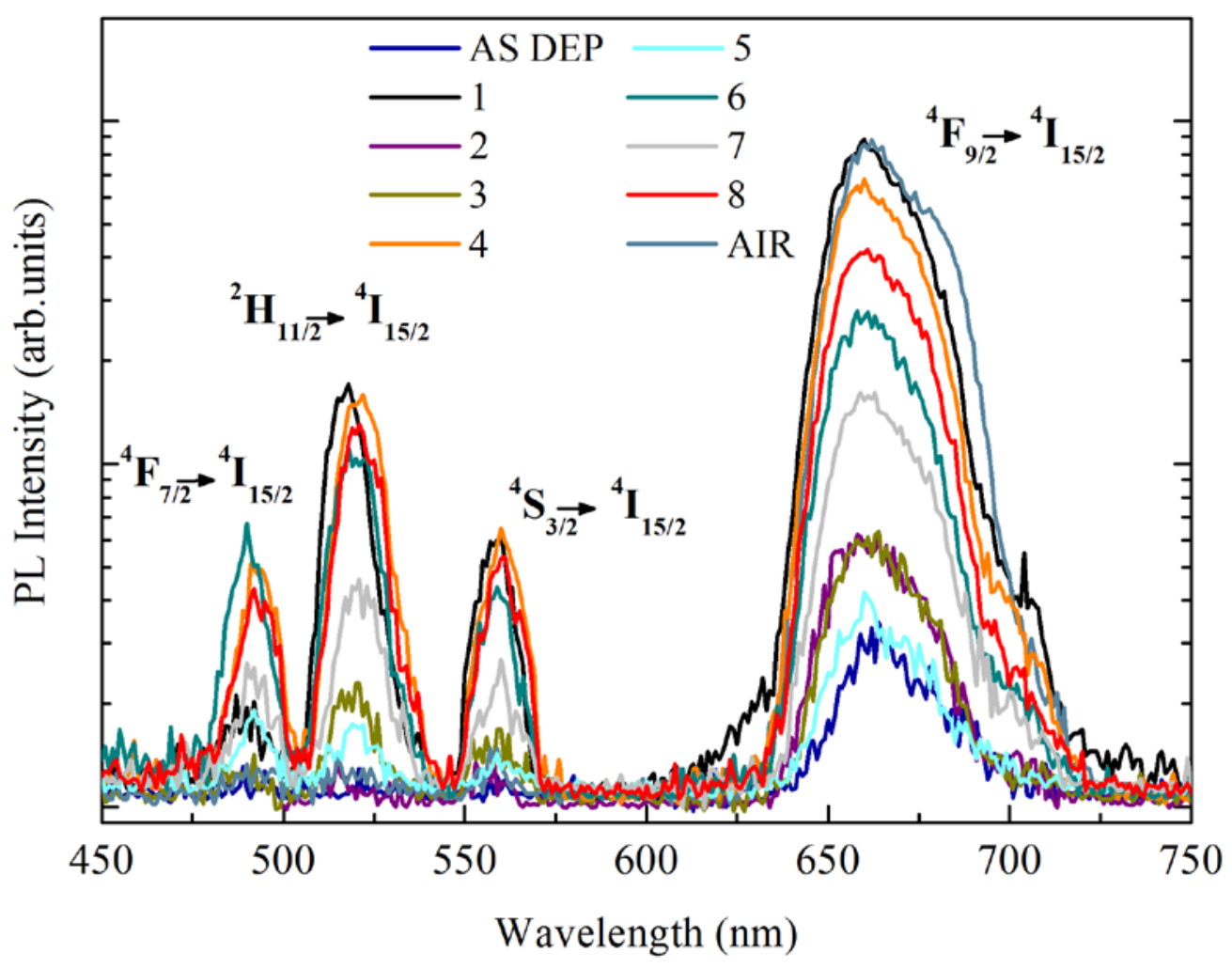

